cesophagus gentle pressure should be employed, soas to makeio traverse the stricture, and as soon as this is done the current may be stopped. My experience of treatment by electrolysis is too small to permit me to confidently express an opinion of its value, but from what I have seen I came to the conclusion that it caused considerable irritation, and probably did more harm than good. So rather than experiment further with patients suffering from oesophageal stenosis, I have been carefully watching the results of the treatment by electrolysis of other more accessible diseases, and as far as I can learn they are not very encouraging.

The last method I will describe to you for relieving the stenosis by an operation from within the gullet is that of internal cesophagotomy. Probably on account of the success which has attended the performance of a similar operation for stricture of the urethra surgeons have been encouraged to divide the obstruction in the gullet by an incision, but the results have been by no means satisfactory. The opera. tion is performed by an cesophagotome, which consists of a gum.elastic bougie, carrying a wire, to the end of which a knife is attached, and by pressing a button, the knife is protruded at will. The curved tube with the knife concealed is passed beyond the stricture, after which the knife is protruded so that it cuts through the stricture on withdrawal of the instrument. In this operation the incision is made from below upwards; in some instances, however, where the oesophagotome could not be passed through the stric. ture, attempts have been made to divide it from above downwards, but such a procedure is highly dangerous, and should in no instance be practised. The circumstances which call for internal cesophagotomy are very exceptional, and to my mind hardly exist. Although it has been performed for malignant and tubercular diseases, I do not think anyone would, on the chance of gaining temporary relief, submit a patient to the dangers attending the operation. Again, in cicatricial stenosis, internal œesophagotomy can be employed only in cases where a bougie of a good size can still be passed, and therefore in a class of cases in which gradual dilatation with bougies or tents might still be used without risk. When you think of the cases which have been broughb under your notice this session, and when I recall those which have come under nay observation, I cannot say that I remember a single instance in which I would feel justified in having this operation performed. When the stricture is situated a little above, at, or below the bifurcation of the trachea, the danger of cutting right through the thin cesophagus, and of injuring the trachea and aorta, or of opening into the posterior mediastinum, is very considerable. Of thirty-two cases where this operation was performed which I have inquired into, nineteen were afforded a more or less permanent inprovement, nine died from the immediate and four from indirect results of the operation, so giving a mortality of a little over 40 per cent.

Within the last few years another operation has been proposed and prastised by Gussenbauer, von Bergmann, and Sands-namely, external cesophagotomy, afterwards dividing the stricture from within, and subsequently allowing the fistula in the neck to heal spontaneously. This operation can only be employed when the stenosis is situated high up; but, on the other hand, when it occupies the lower end of the tube, the stricture has been dilated from below after a preliminary gastrostomy. This operation, said to have been suggested by Schede, has been performed by von Bergmann, Billroth, Studegard, Frittini, Catani, and Loreta, and most of the cases have been successful. (To be concluded.)

\section{RETRO-PHARYNGEAL ABSCESS IN INFANCY AND ITS TREATMENT.}

BY BILTON POLLARD, B.S., F.R.C.S.,

ASSISTANT SURGEON TO UNIVERSITY COLLEGE HOSPITAL AND SURGEON TO THE NORTH-EASTERN HOSPITAL FOR CHILDREN.

RETRO-PHARYNGEAL ABSCESSES were formerly congidered to depend invariably on spinal caries. There is no doubt, however, that this was a mistaken view. The majority of cases occur in quite young children, and in them the pus collects in the cellular tissue between the pharynx and the fascia covering the prevertebral muscles; whilst the tubercular abscesses, which depend on spinal caries, are situated beneath the fascia and ligaments, in close contact with the vertebræ. The relative frequency of the two classes of retro-pharyngeal abscess has been pointed out by Bokai, who collected the records of 204 cases which had been observed at the Children's Hospital in Pesth during a period of twenty-six years. Only seven cases in this large total were dependent on spinal caries, whilst as many as 189 were of a purely local nabure. Judging by the few recorded cases, from the little that is said on the subject in surgical text-books, from my own personal experience and from that of the medical friends whom I have consulted, I am led to think that retro-pharyngeal abscess is a comparatively rare affection in London At the North-Eastern Hospital for Children, where the number of out-patients (new cases) in the year has ranged between 13,000 and 15,000 , I have only met, durno the last five years, with three cases, two of which were under my own care, and one under the care of my colleague Mr. Dean. All three cases were acute, and had no connexion whatever with spinal caries. Although not a common disease, acute retro. pharyngeal abscess of infancy merits a wider recognition than it appears to have obtained, for it not only gives rise to serious symptoms at all times; but it may, by bursting suddenly, especially during sleep, canse death by suffoea. tion, although the condition is one which, if detected, may be completely relieved by a simple enough operation. The following four cases derive additional interest from the manner in which, notwithstanding the amall size and the tender age of the patients, they were treated.

My first case was a male child aged seven months, who was admitted to the children's ward at University College Hospital on April 10 $\mathrm{h}, 1890$, on account of difficulty in breathing. The child had been ill for seven days, at first apparently owing to a nasal catarrh, but during the three or four days previous to admission it had had a "hard and dry" cough, and had had difficulty in both breathing and swallowing. The child was rather rickety. Respiration was accompanied by a snoring sound, chiefly during inspiration, during which also there was slight recession of the ribs and supra-clavicular regions. The child took its food readily, but deglutition was difficult. The back of the tongue was thickly coated, and there was a quantity of thick mucus in the throat. In the notes of the case it is stated that the left tonsil was so much enlarged and reached across to the left side so much that it was almost impossible to get the finger beyond it. No fluctuation was detected. The glands on the left side of the neck below the angle of the jow wera slightly enlarged, whilst in other parts of the body they were not enlarged. The temperature ranged between $98.2^{\circ}$ and $1004^{\circ} \mathrm{F}$. On the day after admission an incision was made into the swelling in the throat and a quantity of pus sponged out. Breathing and swallowing were temporarily relieved, but two days later the child's breathing was very difficult and the swelling in the throat had returned. It was incised again, and a large quantity of pus let oub, with great relief to the child; but in the course of two or three days the swelling began to form again, the temperature rose, and the breathing became more difficult. I saw the child a week after its admission, and found that the abscess did not involve the tonsil at all. It was situated behind the pharynx, chiefly on the left side. I determined to open it from the neck, according to the plan recommex ded by Professor Chiene. A small incision was made along the posterior border of the sterno-mastoid, near its upper end, and carried through all the superficial structures till the muscles in the floor of the posterior triangle were reached. The tissues behind the deep vessels and nerves of the neck were then torn through with blunt instruments sufficiently to admit a finger to such a depth that it could be felt by another finger in the pharynx to be close to the outer border of the abscess. A director was then thrust into the abscess, and as soon as pus was seen escaping, the opening was dilated with a pair of dressing forceps, and a tube was inserted. On the fol. lowing day the swelling in the throat had almost entirely disappeared. Both breathing and swallowing were easy. The vemperature was a little raised for four days in associs. tion with a patch of pneunionia. A tube of smaller calibre was inserted on the second day. The tube was gradually shortened and completely removed on the ninth day after the operation. The child was discharged a month after the operabion, since which it had no difficulty either in breathing or swallowing.

My second case occurred at the North Eastern Hospital. 
The child was a female, aged thirteen months. She was admitted on April 11th, 1891. For the last three months and a balf the child had had a discharge from its left ear. Ten weeks ago the lymphatic glands on the left side of the neck, both in front of and behind the sterno-mastoid muscle, began to enlarge. Eight weeks ago a small abscess burst just below the left angle of the lower jaw, and healed up in about a week. During the last month breathing had been noisy, especially during sleep, from which the child frequently awoke gasping for breath. During the last month also deglutition had been difficult. Liquids were often regurgitated $a b$ once. On admission to the hos. pital the child was pale and flabby, and presented slight signs of rickets. The child breathed fairly well. On examining the pharynx, a swelling was seen on the left side extending from the posterior part of the tonsil to rather beyond the middle line. It reached upwards beyond the soft palate, and its lower limit could only just be felt. The swelling was very tenge, but elastic. There were no signs of spinal caries. The abscess was opened externally in the manner described in the last case. The cavity of the abscess was scrubbed out with a piece of sponge and drained by a long tube. The symptoms at once subsided. Respiration and deglutition were henceforth normal. The tabe was shortened very slowly in order to avoid reaccumulation. The glandular swellings quickly subsided, and the child was quite well three weeks after the operation, and continued so when last seen three months later.

The third case, a female child aged two years and one month, was admitted to the North. Eastern Hospital on Sept. 14th, 1891. The child had been noticed to be "out of sorts" for about a week. Two days before admission the child began to make a peculiar noise during inspiration, got rather blue in the fdce, and coughed up a quantity of froth. Daring the day and night before admission the child had repeated fits of choking. On admission, the child was pale, thin, and weak-looking. Its volce was hoarse; respiration was noisy but not difficult when the child was awake, though during sleep it was distinctly laboured, and the child frequently woke up with a start. The glands in the neck about the angle of the jaw were slightly enlarged. There were no signs of spinal caries. The back of the pharynx was found bulged forwards by a swelling, which on the right side reached to the lateral wall and on the lef side to about a quarter of an inch from it. The upper limit of the swelling was on a level with the soft palate, when it WRS dependent. and the lower limit was opposite the top of the larvnx. Fluctuation could be detected in the swelling. The abscess was opened through an incision an inch in length along the posterior border of the sterno-mastoid, about an inch below the mastoid process. The dissection was then carried on with blunt instruments behind the deep ressels and nerves until the swelling was reached. A director was then thrust in to the abscess and the opening was enlarged with dressing forceps. About an ounce of pus was let out. The cavity was mopped out with 1 in 500 solution of perchloride of mercury, drained, and dressed with sal alembroth gauze and wool. After the operabion the symptoms did noo improve-in fact, they got gradually worse. The temperature still ranged between the normal and $101^{\circ}$. On the third day after the operation the child began to get rather cyonosed, and had frequent fits of dyspnce. She was put in a steam-tent and hot fomentations were applied to her neck. I saw the child again on the fourth day after the operation, and found that the swelling at the back of the pharynx was larger than ever. A steel director was passed in through the wound, and about two ounces of pus were let out. The tube was not lying in the abscess cavity. Io was replaced. During these manipulations the child was nearly asphy xiated ; but when they were completed she fell asleep immediately, and continued sleeping quietly for the next twelve hours, excepting wben she was roused up to take food. There was no further difficulty with breathing. The temperabure now fell, and in a few days was normal. On the third day after the second operation the retro-pharyngeal swelling had almost subsided and the voice had almost lost its hoarseness. There was an abundant diacharge from the tabe, which was slowly shortened, and not left out entirely until the twenty-third day. The child was sent home on the following day, and ten days later she was perfectly well.

The fourth case which has come under my notice was under the care of my colleague Mr. Dean, to whom I am indebted for permission to include it in this paper. The patient was a male child aged seventeen months. She was admitted to the North-Eastern Hospital on Oct. 13th, 1891. Ten days before admission the child had a "general cold." Three days later its breathing was troublesome at night. The difficulty in breathing got gradually worse, and some difficulty in swallowing also came on. The child when admitted to the hospital was suffering with intense dyspnca. There was marked recession of the chest and the face was livid. The right side of the neck was rather swollen. The posterior wall of the pharynx was very red and tense, and was pushed so far forwards that it almost blocked the fauces. The swelling, in which distinct fluctuation could be detected, extended upwards to the base of the skull and downwards to the top of the larynx, and laterally, on each side, to the posterior pillars of the fauces. The condition of the patient, owing to the obstruction to the respiration, was extremely urgent. Mr. France, the house surgeon, performed intubation with one of $O^{\prime} D$ wyer's tubes (suited to a child between two and three years old) quite readily; but, as soon as he removed his finger, the swelling bagged over the end of the tube and blocked it. Respiration had now ceased, and so Mr. France decided, in my opinion wisely, rather than trust to the chance of being able to re-establish respiration, after opening the abscess in the throat, to perform tracheotomy at once. This he did, and, after stimulation and artificial respiration, the child came round and went to sleep, breathing easily through a Purker's tube. It was now about $11.30 \mathrm{~A}$ M. Mr. Dean saw the patient shortly afterwards, and decided not to open the abscess until the child had recovered somewhat from its exhausted state. At 9 P.M. Mr. Dean made an incision three quarters of an inch in length along the posterior border of the sterno-mastoid muscle and an inch below the mastoid process, and after dividing the fascia beneath the muscle, the pus was quickly reached, and two ounces were evacuated. The abscess cavity was explored with the finger, but no signs of cervical caries were found. The cavity was washed out with 1 in 2000 solution of perchloride of mercury, drained with a large tube, and dressed with boracic fomentations. For two nights and days the child remained in a very restless and exhausted state, but after that time it began to improve. The temperature, which had reached $102 \cdot 2^{\circ} \mathrm{F}$., did not fall to the normal till the fourth day, and the tracheotomy tube could not be left out permanenbly till the sixth day after the operation. On the twenty-second day the tracheotomy wound had closed, and the tube was left out of the abscess cavity. The child was discharged well three days later.

All the four cases above recorded recovered completely, the abscess cavity closing up quickly. The abscess in each had clearly no relation to spinal caries; it was evidently an entirely local affection. In none of them was the tonsil the seat of the abscess, and, in faet, so far as my observa. tion goes, tonsillar abscess is very rare, if it occurs at all, in such young children as were those whose cases have just been narrated. Two views have been advanced to explain the origin of these acute retro-pharyngeal abscesses which occur in young children. One is that they depend on an acute phlegmonous inflammation induced in a similar manner to acute abscesses elsewhere; and the other is that they are dependent on an adenitis which is secondary to inflammation of one of the neighbouring mucous surfaces. In connexion with the latter view we have an important observation by Dr. Edmund Simon, ${ }^{\mathrm{I}}$ who describes the lymphatics of the retro-pharyngeal region as forming networks on each side, which terminate in glands located one on each side of the median line between the pharynx and the aponeurosis of the prevertebral muscles. He further states that the glands disappear altogether after the third year of life. In striking agreement with this observation is the fact that the majority of acute retro-pharyngeal abscesses occur in quite young children. The ages of the four cases recorded above were seven months, thirteen months, twenty-five months, and seventeen months. The great majority of Bokai's cases occurred in children under two years of age, and 196 out of his 204 cases occurred under three years. Henoch ${ }^{2}$ says that almost all his cases occurred in children still in their first year or little beyond it. In equal agree-

1 Schmidl's Jahrb., Band. crii., p. 161, quoted by Blackader in a valuable paper published in the Archives of Pediatrics, vol, vi., p. 80 . 2 Lectures on Children's Diseases, Sydenham Society's Translation, 
ment with Simon's observation is the fact that the abscess is usually unilaterally placed. This was so in my three cases. The primary inflammation from which the glands are infected may involve the pharynx, the posterior part of the nasal fossa, the fauces, or the tympanum. In two of the cases above recorded the first sign of illness was a nasal catarrb, and in one an otitis on the same side of the body as the retro-pharyngeal abscess was situated. The disease may come on either very acutely or somewhat insidiously. If the abscess is situated behind the upper part of the pharynx, deglutition will be chiefly embarrassed; but if it be situated lower down, respiration will be also impeded. The difficulty in breathing is especially noticeable during sleep, when, too, it may be accompanied by snoring. The voice, as in one of my cases, may be hoarse, owing to associated laryngeal catarrh. The lymphatic glands on one or both sides of the neck are generally swollen. These symptoms are sufficiently sug gestive to lead to an examination of the throat, when if there is a retro-pharyngeal abscess a soft and fluctuating swelling, situated usually rather to one side of the middle line, and bulging the posterior wall of the pharynx forwards, may be felt.

As soon as a retro-pharyngeal abscess is diagnosed steps should be taken to open it, lest urgent dyspncea come on (as happened in one of the cases recorded in this paper), or in case the abscess burst when the child is asleep or when assistance is not at hand, and the matter be sucked into the larynx and cause suffocation. There are two possible methods of opening the abscess. It may be opened by an incision through the pharyngeal wall or by an external incision in the neck. The first plan is no doubt the most enticing, owing to the ease with which it can be carried out, but it is not free from objection. The abscess cavity cannot be drained with a tube when the opening is into the pharynx, and consequently the incision may close too soon and the pus may reaccumulate. This occurred in my first case; and, indeed, it was this repeated reaccumulation which led me to dissect down from the outside, after the plan recom. mended by Professor Chiene, notwithstanding the small size and tender age of the patient. Again, proper antiseptic treatment is impossible when the abscess has been opened in the pharynx. If, however, this plan is adopted, the child should be put under the influence of chloroform, the mouth should be gagged open, and the head should hang rather over the end of the table. The abscess should then be opened by a longitudinal incision reaching the entire length of the swelling, and the pus should be rapidly sponged away, so as to prevent any of it finding its way in to the larynx.

Professor Chiene's plan of opening chronic retro-pha. ryngeal abscesses dependent on spinal caries is well known; but I am not aware that it has been adopted for the acute abscesses occurring in infancy, unless the pus was pointing externally. There is, however, no difficulty in performing the operation even when the abscess is small and confined to the retro-pharyngeal tissue, and when the patient is quite a young child. In my first case the abscess was not only strictly retro-pharyngeal, but it had been partially drained into the pharynx, and the child was only seven months old. The operation was done as follows in all the cases. An incision, about an inch in length, and about an inch below the mastoid process, was made along the posterior border of the sterno-mastoid. After the fascia covering the muscles in the floor of the posterior triangle was exposed, a cautious dissection with blunt instruments was made behind the deep vessels and nerves of the neck until one finger placed in the wound almost met another placed in the pharynx. A director, guided by the finger in the pharynx, was then thrust into the abscess, and the opening enlarged by passing a pair of dressing forceps into it and forcibly separating the blades. A drainage-tube should be inserted, and care should be taken that it does not slip out of the abscess cavity, as happened in one of my cases, and give rise to reaccumulation of pus.

Harley.street, w.

The Small-POX AT Batley.-The Batley Corpora tion have now arranged to make considerable addition to the isolation hospital near Howden Clough, the alterations being mainly for convalescent purposes.

\section{ACUTE CATARRH OF THE LARYNX.}

\section{BY GORDON HOLMES, M.D.,}

PHYSICIAN TO THE MUNICIPAT THROAT AND EAR INFIRMARY, LONDOY CONSULTING PHYSICIAN TO THE SHEFEIELD EAR AND THROAT HOSPITAL.

$$
\text { (Concluded from page } 305 .)
$$

Pathological anatomy \&c. - In addition to the objective appearances revealed laryngoscopically, the closer inepection to be obtained in the post-mortem room allows the reco. gnition of other changes in the laryngeal mucous membrane. Thus the nsual proliferation and shedding of epithelium consequent on inflammation of mucous tissue can be accu. rately studied. Catarrhal erosions may thus be seen in patches where the epithelium falling away has laid bare the basement membrane. Such erosions may even oceur on the free edges of the vocal bands, marring the even outline of the parts, so as to be visible during life with the laryngoscope. According to Krishaber, ${ }^{2}$ other ulcers, which he calls "glandular erosions," not larger than a pins" head, may also be present, surrounding the orifices of the mucous follicles. Tumefaction of these mucous glands is also generally present, and when the tissues are put on the stretch by manipulation their openings give exit to a puru lent secretion. Distension and rupoure of minute veins, producing numerous ecchymosed points, are also commonly to be noted. In some cases the redness of the larynx observed ocularly during life is found to have almost disappeared after death, a phenomenon which is explained though insufficiently, by cadaveric retraction of the elastic fibres which form so large a part of the mucoid derma Microscopic examination of the expectorated matters shows the presence of all the elements of epithelial disintegrtion just spoken of, together with both white and red hloodcorpuscles, even when no sanguineous tinge is visible to the naked eye. When the disease is at its height a great part of the mucous discharge consists of pus cells. The source of the pus in inflammation of this kind is still a question of some obscurity. According to Eberth ${ }^{2}$ and others it consists of altered cells of cylindrical epithelium; in proof of which they point to their being frequently observed to retain indetinitely the vibratile cilia. Rindfleisch, ${ }^{3}$ again, is still inclined to regard the pus cells as for the most part connertive-tissue corpuscles, emanating from the body of the mucous membrane, which proliferate and make their way to the surface by the amceboid movements so characteristic of young cells. It seems simpler, however, to accept the well-known doctrine of Cohnheim, who sees in catarrhal pus merely the exuda tive white blood-corpuscles. As regards the pellets of mucus of ten brought up, they, as Krishaber ${ }^{4}$ suggests, most probably indicate that the catarrh affects the interior of the laryngeal ventricles, where the discharge collects until it attains a certain consistence and volume, and is then extruded by some act of coughing or deglutition.

We have now to consider the suffocative attacks which are often so striking a feabure when the affection occurs in children. Here the explanatory statements, which so far have been made, are entirely conjectural. Thus, Niemeyer, after reviewing the circumstances of the accessions, remarks that "it would be natural to admit that a viscid secretion accumulating in the glottis dries there, probably agglutinates the edges of the vocal bands, and thus gives rise to the attacks of dyspncea." Mackenzie ${ }^{6}$ also adopts this view, though without referring to Niemeyer as its prior exponent. Krishaber, ${ }^{7}$ again, seeks the cause in "the very slight development of the cartilaginous glottis in children," which renders the glottic chink very narrow. Hence the inflammatory stenosis, though of comparatively minor degree, is able to occasion such urgent symptoms, when aided by " the relaxation of respiratory action which occurs during sleep." Neither of these hypotheses seems to me to take us very far on the path of elucidation, and the

1 Dict. des Sciences Méd., 1868, art. Larynx.

${ }^{2}$ Zur Enstehung der Schleimkorper, Virchow's Auchiv, Bd, xxi. 1861, S. 106. See also Cornil and Hérard, La Phthisie, Paris, 186 4 , p. Lehrb. der Path. Gewebelehre, Leipzig, 1886, p. 109 et seg. 4 Op. cit.

5 Lehrb. der Spec. Pathol. und Therapie, Berlin, 1858, p. 7. Diseases of the Throat, 1880, p. 267. Op. cit., p. 601 . 